\title{
Uma análise de procedimentos metodológicos executados numa disciplina de Matemática na Pós-Graduação durante a pandemia da COVID-19
}

\author{
An analysis of methodological procedures applied in a mathematics graduate \\ course during the COVID-19 pandemic
}

\author{
Ricardo Fajardo (iD https://orcid.org/0000-0002-9416-713X \\ Universidade Federal de Santa Maria \\ e-mail-rfaj@ufsm.br
}

\author{
Samuel Sonego Zimmermann (D) https://orcid.org/0000-0002-1000-8714 \\ Universidade Federal de Santa Maria \\ e-mail - ssz.profmat@gmail.com
}

\section{Resumo}

O objetivo do presente artigo é analisar se os procedimentos metodológicos usados na disciplina, ministrada no formato de Regime de Exercícios Domiciliares Especiais durante a pandemia da COVID-19, resultaram num momento de aprendizagem satisfatório para os acadêmicos. Para tanto, elencou-se os objetivos específicos de apresentar a metodologia usada na disciplina durante o período sem pandemia; discutir desafios, reflexões e ações visando sanar as inquietações geradas durante o desenvolvimento da disciplina; e identificar as impressões dos acadêmicos com relação à metodologia aplicada. O procedimento central consistiu na produção de vídeos de curta duração, usando como referencial teórico a Teoria da Carga Cognitiva, primando minimizar a carga estranha e maximizar as cargas intrínseca e relevante. Aplicou-se um questionário aberto para obter os dados. As respostas às perguntas mostraram que os resultados do método adotado foram satisfatórios, vídeos de até 15 minutos, produzidos para os momentos assíncronos, receberam uma avaliação positiva e estimuladora. Na produção desses vídeos foi necessário exercitar a capacidade de ser claro, direto e sucinto, o que normalmente não ocorre numa aula presencial. Para um vídeo explicativo de curta duração, verificou-se que os acadêmicos se sentiriam muito mais estimulados em revê-lo, contrapondo com a dificuldade de assistir a um vídeo de duas horas ou mais, visto que ainda não há uma ferramenta universal de busca num vídeo qualquer, como existe no arquivo em formato PDF, que permite procurar por palavras dentro do texto. Finalmente, questiona-se se a aula presencial será a mesma no período pós-pandemia.

Palavras-chave:Processo de ensino-aprendizagem. Tecnologia educacional. Educação matemática. 


\begin{abstract}
This article's intent is to analyze whether the methodological procedures used in a course, given in the format of Special Home Exercises Regime during the COVID-19 pandemic, resulted in a moment of satisfactory learning for the students. To this end, we listed the specific objectives of presenting the methodology used in the discipline during the period without pandemic; discuss challenges, reflections and actions to address the concerns generated during the development of the course; and identify the students' impressions concerning the applied methodology. The main procedure consisted in producing short videos, based on the Theory of Cognitive Load, intending to minimize the strange load and to maximize the intrinsic and relevant loads. An open questionnaire was applied to obtain the data. The answers to the questions showed that the results of the adopted method were satisfactory, with videos of up to 15 minutes, produced for the asynchronous moments, received a positive and stimulating evaluation. In preparing these videos it was necessary to exercise the ability to be clear, direct and succinct, which usually does not occur in a regular classroom. For a short explanatory video, it was found that students would feel much more inclined to review it, as opposed to the challenge of watching a video of two hours or more, as there is not yet an universal search tool for any video, as it exists in a PDF file, which allows searching for words within the text. Finally, it is questioned whether or not the regular classroom will be the same in the post-pandemic period.
\end{abstract}

Keywords: Teaching-learning process. Educational technology. Mathematical education.

\title{
Introdução
}

Em 9 de março de 2020 iniciou-se o primeiro semestre na Universidade Federal de Santa Maria (UFSM). Passada uma semana, a UFSM publicou a Instrução Normativa 2/2020/PROGRAD, que determinava a suspensão de todas as atividades acadêmicas e administrativas presenciais, em decorrência da Pandemia COVID-19. Essa normativa regulava o Regime de Exercícios Domiciliares Especiais (REDE). No seu Art. 7. ${ }^{\circ}$, ficava a critério do docente aderir ou não ao REDE. O docente que decidisse aderir deveria, durante o período de suspensão, utilizar-se de

[...] meios virtuais para o seu andamento, dentre eles: I - Ambientes Virtuais de Ensino-Aprendizagem, a exemplo do Moodle; II - E-mail; III - Grupos Específicos em Redes Sociais; IV - Skype; V Aplicações do G Suite for Education; VI - outras formas de compartilhar recursos e aplicar/avaliar atividades escolhidas pelo docente da disciplina e acessíveis aos estudantes. (Universidade Federal de Santa Maria, 2020, p. 2)

Como docente da disciplina "Estruturas Algébricas: com um foco no conjunto dos números reais"1, ministrada no Programa de Pós-Graduação em Educação Matemática e Ensino de Física (PPGEMEF), nível de Mestrado, decidimos aderir ao REDE. O distanciamento social imposto é muito similar à quarentena que, muitas vezes, "[...] é uma experiência desagradável para aqueles que passam por isso. Separação dos entes queridos, a perda de

\footnotetext{
${ }^{1}$ A disciplina totalizava 60 horas no semestre, e cada encontro teve a duração de 4 horas.
} 
liberdade, incerteza sobre o estado da doença, e o tédio podem, por vezes, criar efeitos dramáticos" (BROOKS et al., 2020, p. 912, tradução nossa). Sendo assim, com o intuito de manter o vínculo com a universidade e de continuar com uma rotina de estudos previamente estabelecida, assumimos lecionar esta disciplina no modelo REDE. Acreditávamos que tal continuidade de hábito iria auxiliar-nos, como docente e como acadêmico, a manter a sanidade mental. Essas são algumas justificativas para nossa adesão ao Regime de Exercícios Domiciliares Especiais.

Dessa forma, remetemo-nos ao objetivo geral da pesquisa, a saber: Analisar se os procedimentos metodológicos usados na disciplina, ministrada no formato REDE, resultaram num momento de aprendizagem satisfatório para os acadêmicos. Os objetivos específicos elencados foram: (1) apresentar a metodologia usada na disciplina durante o período sem pandemia; (2) elencar desafios, reflexões e ações visando sanar as inquietações geradas durante o desenvolvimento da disciplina no formato REDE; (3) Identificar as impressões dos acadêmicos com relação ao procedimento metodológico da disciplina de Estruturas Algébricas.

A pesquisa classifica-se como qualitativa, visto que ela "objetiva, em geral, provocar o esclarecimento de uma situação para uma tomada de consciência pelos próprios pesquisados dos seus problemas e das condições que o geram [...]" (CHIZZOTTI, 2017, p. 128). Ou seja, desejamos saber se os procedimentos metodológicos usados resultaram num momento de aprendizagem satisfatório para os acadêmicos. Nesse contexto, o "pesquisado" é o próprio docente. Uma premissa subjacente a esse tipo de pesquisa é "o conhecimento [que] conduz a uma ação, e a pesquisa pode ser uma oportunidade de formar os pesquisados a fim de que transformem os problemas que enfrentam" (Ibid, p. 129); nesse caso, o problema enfrentado (o desafio) é o uso de um novo método, estranho a nós.

O público alvo foi composto de dez acadêmicos matriculados na disciplina. $A$ coleta de dados foi efetuada através de um questionário com perguntas abertas. No início dele apresentamos um Termo de Consentimento Livre e Esclarecido (TCLE), em que garantimos o anonimato dos participantes e solicitamos o seu consentimento em participar da pesquisa. No primeiro semestre de 2020, essa disciplina teve dez acadêmicos matriculados. Desses, sete responderam ao questionário.

Segundo Chizzotti, "o questionário consiste em um conjunto de questões préelaboradas, [...] que constituem o tema da pesquisa, com o objetivo de suscitar dos informantes respostas por escrito [...] sobre o assunto que os informantes saibam opinar ou informar". (Ibid, p. 69). As perguntas e respostas serão elencadas ao longo do desenvolvimento do texto, à medida que também apresentamos reflexões e ações futuras, instigadas por tais respostas.

\section{Desenvolvimento}

Esta seção está dividida em quatro subseções: (a) a metodologia de ensino e aprendizagem em tempos de não pandemia na disciplina; (b) a metodologia de ensino e aprendizagem em tempos de pandemia na disciplina, parte I; (c) 
o referencial teórico; (d) a metodologia de ensino e aprendizagem em tempos de pandemia na disciplina, parte II; e (e) as discussões que ocorrem ao longo da apresentação das respostas às perguntas do questionário. A seção (a) é apresentada com o intuito de comparar com o momento de pandemia apresentado nos itens (b) e (d). O referencial teórico, item (c), é apresentado nesta sequência com o objetivo de explicitar a revisão bibliográfica da Teoria da Carga Cognitiva, que é o cerne do procedimento adotado, no momento em que ela se faz necessária, de maneira que haja uma continuidade de ideias. No entanto, ao longo do texto também conversaremos com outros teóricos, buscando legitima os nossos argumentos.

\section{A Metodologia de Ensino e Aprendizagem em tempos de não Pandemia na Disciplina}

Nos anos anteriores, quando não havia a pandemia do COVID-19, atuávamos como mediador. O objetivo era trabalhar aplicando a metodologia do trabalho em grupo. Para tanto, solicitávamos a formação de grupos, cujo tamanho dependia do número total de acadêmicos matriculados.

O trabalho em grupo na sala de aula é socializador. Ele vai ao encontro da aprendizagem do interpsíquico ao intrapsíquico (VIGOTSKY, 2000, 2002); ou seja, do social (neste caso, o grupo) para o individual, dessa forma auxiliando na compreensão do conteúdo.

Iniciávamos com uma intervenção, introduzindo o conteúdo a ser estudado naquele encontro. Durante a execução das tarefas em grupo, circulávamos pela sala de aula, observando e somente intervindo se julgássemos necessário ou se alguém formulasse alguma pergunta que o grupo não conseguia responder por si próprio. Quando todas as dúvidas eram dirimidas, alguém apresentava a solução na lousa; e na sequência a discussão era socializada.

Durante o semestre, todos os acadêmicos deveriam apresentar na lousa pelo menos uma vez. Entretanto, ocorria que cada um acabava apresentando várias vezes.

O processo de avaliação consistia de dois momentos: o primeiro era a participação ativa na realização das tarefas durante as aulas, incluindo a apresentação na lousa. O segundo consistia no preenchimento de um formulário de autoavaliação, onde eram respondidas as seguintes perguntas: (1) Nome; (2) Na sua opinião qual deveria ser a sua nota nesta disciplina?; (3) Justifique a resposta do item (2). Dessa forma, a avaliação envolvia um processo formativo e reflexivo (FERNANDES; FREITAS, 2007) e consistiu em um instrumento orientador da atividade de ensino do professor e da aprendizagem do estudante (FAJARDO; LOPES, 2017).

\section{A Metodologia de Ensino e Aprendizagem em tempos de Pandemia na Disciplina: desafios e reflexões (Parte I)}

Com o início do isolamento social, que iniciou em 17 de março de 2020 na UFSM, vários acadêmicos matriculados na disciplina retornaram à sua cidade

Revista de Estudos e Pesquisas sobre Ensino Tecnológico, v. 6, Edição Especial Desafios e Avanços 4 Educacionais em Tempos da COVID-19, e155720, 2020. 
natal, para a casa de seus familiares. Sendo assim, o primeiro desafio que se apresentou foi como poderíamos usar um Ambiente Virtual de Ensino e Aprendizagem (AVEA) para desenvolver o conteúdo da disciplina, visto que estávamos acostumados às aulas síncronas e presenciais. A universidade já disponibilizava aos seus docentes os AVEA: a Plataforma Moodle ${ }^{2}$ e o G Suite for Education ${ }^{3}$.

Até aquele momento, nós já usávamos a Plataforma Moodle como um repositório às aulas presenciais. Após uma semana, estávamos cientes de que nem todos os acadêmicos teriam um acesso contínuo à Internet, e aqueles que contavam com ele informaram que não tinham estabilidade de conexão. Dessa forma, ficou evidenciado que os momentos síncronos não poderiam ser um fator essencial, predominante, ao longo do semestre. Do contrário, esses acadêmicos ficariam prejudicados, pois não teriam a oportunidade de participar ativamente, fazendo perguntas, emitindo opiniões - enfim, participando do momento síncrono. Portanto, o momento síncrono não poderia ser um fator essencial no processo avaliativo.

Além do mais, havia a preocupação de como planejar os momentos assíncronos, com o conteúdo postado na Plataforma Moodle, incluindo um vídeo explanando-o. Então, surgiu a pergunta: qual deveria ser o tempo de duração dos vídeos? Por conseguinte, remetemo-nos à Teoria da Carga Cognitiva (TCC), que leva em consideração as cargas intrínseca, estranha e relevante, bem como as memórias de trabalho, de curto prazo, e memória permanente, de longo prazo. Como julgamos tal teoria relevante à nossa experiência, divagaremos aqui momentaneamente para discursar brevemente sobre ela.

\section{Referencial Teórico: Sobre a Teoria da Carga Cognitiva (TCC)}

A Teoria da Carga Cognitiva foi elaborada em 1976 por John Sweller (SWELLER, 1976), psicólogo australiano, professor emérito da Universidade de New South Walles, em Sydney, na Austrália. O principal intuito da teoria é formar esquemas mentais e automatizá-los, na tentativa de reduzir a carga cognitiva. Essa carga consiste no esforço mental para aprender algo novo.

Segundo Atkinson e Shiffrin (1968), a estrutura cognitiva é dividida em três componentes: o registro sensorial, a memória de curto prazo e a memória de longo prazo. O registro sensorial tem a função de consignar estímulos apresentados, os quais podem ser auditivos, verbais ou linguísticos. Eles são "copiados" ou transferidos para a memória de curto prazo, também chamada "memória de trabalho", onde se processam os registros sensoriais. Por fim,

\footnotetext{
${ }^{2}$ A Plataforma Moodle é um pacote de código aberto que permite que as universidades, entre outras, use o software da maneira mais adequada. Oferece uma interação entre o professor e o aluno através de várias ferramentas tais como: vários tipos de fóruns (discussão, notícias, perguntas e respostas), produção de atividades para upload, preparação de avaliações online, o BigBlueBbutton para videoconferências, atividades Wiki para trabalho colaborativo, etc. Disponível em: www.moodle.com.

${ }^{3} G$ Suite for Education é um pacote de propriedade da Google. Oferece vários produtos do Google que podem ser personalizados ao gosto do professor, tais como: Google classroom, Google Meet, email, etc. Disponível em: edu.google.com.
} 
são transferidos à memória de longo prazo quando a aprendizagem se consolida.

A TCC consiste de três cargas, a saber: intrínseca, estranha e relevante. A seguir, apresentamos a descrição de cada uma.

\section{TCC: Sobre a carga intrínseca}

A carga intrínseca é a carga cognitiva contida no próprio conteúdo, ou seja, é a complexidade intelectual de tal informação; ou, ainda, é um conjunto de esquemas intrínsecos (internos) do conteúdo.

Sweller e Chandler (1994) postulam que a informação é composta de elementos que podem interagir entre si. Essa interação entre elementos é muito presente na Matemática. Um exemplo disso encontra-se na definição de algum ente teórico, na qual existe uma grande carga de significado intrínseco em cada palavra presente, tornando o seu entendimento complexo.

Um exemplo mais específico seria a definição de função derivada. Embutidas nesta definição há: (1) do ponto de vista da Matemática Pura: função, limite, inclinação de retas secantes e tangentes a um gráfico; (2) do ponto de vista da Matemática Aplicada: função representando, entre outros, o deslocamento ou a velocidade de um objeto, o limite, a taxa de variação média e instantânea. Além do mais, no próprio conceito de função há uma miríade de elementos com carga intrínseca, notadamente: os números reais, as quatro operações aritméticas, variável, potenciação, logaritmos, e assim sucessivamente.

\section{TCC: Sobre a carga estranha}

A carga estranha, carga alheia ou carga ineficaz, mencionada por Artino (2008), é aquela contida na comunicação entre o aluno e o professor. Essa carga deve ser sempre minimizada, ou seja, o professor deve ter a habilidade de apresentar, "passar ou transmitir" as informações de forma eficiente.

A carga estranha consiste na parte irrelevante ao aprendizado do aluno: informações, afirmações ou fatos que não estão ligados com o conceito central da aula ou da informação apresentada. Assim, podemos inferir que, quando o professor não possui domínio pleno do conteúdo, certamente irá compor uma carga estranha elevada, pois não estará ciente das principais dificuldades que os alunos podem apresentar nesse conteúdo.

Outro exemplo de uma carga estranha na sala de aula seria o professor ter a lousa completamente preenchida e, ao responder a pergunta de um aluno, rabiscar entre as informações já escritas. Essa mistura de informações pode atrapalhar o entendimento e não sanar a dúvida do aluno.

\section{TCC: Sobre a carga relevante}

Para determinarmos a carga cognitiva, devemos levar em conta a soma das cargas intrínseca, estranha e relevante, e esse resultado não deve ultrapassar a capacidade da memória de trabalho - memória temporária ou de curto prazo. 
A carga relevante é considerada como a carga cognitiva para lidar com a aprendizagem, ou seja, a carga que estaria associada aos processos relevantes para a aprendizagem, contrapondo-se à carga estranha, que está ligada a processos que não ajudam na aprendizagem.

Se nenhuma parte da carga intrínseca é tratada com sucesso, a carga relevante é considerada zero, com relação à aprendizagem. Novamente, vamos considerar o caso da Matemática, quando é apresentado um conceito de equação do primeiro grau e os alunos não reconhecem as propriedades da igualdade para obter a resolução da equação, mas, mesmo assim, conseguem resolvê-la. Temos aí um exemplo de que parte da carga intrínseca não foi transformada em carga relevante.

Clark, Nguyen, e Sweller (2006), no seu livro intitulado "Efficiency in Learning: evidence-based guidelines to manage cognitive load" 4 apresenta 29 diretrizes para melhorar o processo de ensino e aprendizagem através do gerenciamento da carga cognitiva (SOUZA, 2010). A seguir, apresentamos as diretrizes que são essenciais à pesquisa em questão.

Terceira diretriz: Use diagramas para ajudar os aprendentes a construir uma compreensão mais profunda (CLARK; NGUYEN; SWELLER, 2006 apud SOUZA, 2010, p. 126).

Quarta diretriz: Explique diagramas com palavras apresentadas em 'áudio-narração (Ibid, p. 127).

Oitava diretriz: Reduza o conteúdo ao essencial. (Ibid, p. 133).

Nona diretriz: Elimine visuais, texto e áudio estranhos ao conteúdo a ser aprendido. (Ibid, p. 134).

Décima sexta diretriz: Dê aos aprendentes o controle sobre o ritmo e gerencie a Carga Cognitiva quando o ritmo tiver de ser controlado pelo sistema instrucional. (Ibid, p. 137).

Após apresentarmos brevemente o cerne da Teoria da Carga Cognitiva, continuamos com a apresentação da pesquisa.

\section{A Metodologia de Ensino e Aprendizagem em tempos de Pandemia da Disciplina: desafios e reflexões (Parte II)}

Com base na Teoria da Carga Cognitiva, concluímos que os vídeos que deveriam ser postados na Plataforma Moodle para os momentos assíncronos não deveriam ser muito longos. Além do mais, para uma mesma aula houve momentos em que postamos até três vídeos, cada um com curta duração. A ideia de vários vídeos foi apresentada com o intuito de focar num único tópico, diminuindo a carga estranha e aumentando a carga relevante, em relação à carga intrínseca do conteúdo trabalhado. Dessa forma, os vídeos tiveram uma duração de, aproximadamente, 5 a 15 minutos, conforme o quadro 1.

Quadro 1 - Distribuição de vídeos e videoconferências na disciplina

\begin{tabular}{|c|c|c|c|}
\hline Aulas & Vídeo/Duração & Aulas & Vídeo/Duração \\
\hline
\end{tabular}

\footnotetext{
${ }^{4}$ Eficiência na Aprendizagem: diretrizes baseadas em evidências para gerenciar a carga cognitiva. 


\begin{tabular}{|c|c|c|c|}
\hline Aula 1 & Presencial & Aula 9 & $\begin{array}{l}\text { Vídeo 1: 06:20 } \\
\text { Vídeo 2: 02:59 } \\
\text { Vídeo 3: 10:14 }\end{array}$ \\
\hline Aula 2 & $\begin{array}{l}\text { Vídeo 1: 03:37 } \\
\text { Vídeo 2: 04:06 } \\
\text { Vídeo 3: 02:38 }\end{array}$ & Aula 10 & Vídeo 1: 15:02 \\
\hline Aula 3 & $\begin{array}{l}\text { Vídeo 1: 03:40 } \\
\text { Vídeo 2: 03:36 } \\
\text { Vídeo 3: 02:33 }\end{array}$ & Aula 11 & $\begin{array}{l}\text { Vídeo 1: 15:25 } \\
\text { Vídeo 2: 09:24 } \\
\text { Vídeo 3: 03:26 }\end{array}$ \\
\hline Aula 4 & $\begin{array}{l}\text { Vídeo 1: 03:11 } \\
\text { Vídeo 2: 02:40 } \\
\text { Vídeo 3: 02:35 } \\
\text { Vídeo 4: 05:17 }\end{array}$ & Aula 12 & Vídeo 1: 06:41 \\
\hline Aula 5 & $\begin{array}{l}\text { Vídeo 1: 04:39 } \\
\text { Vídeo 2: 04:23 }\end{array}$ & Aula 13 & $\begin{array}{l}\text { Videoconferência } \\
\text { Vídeo 1: 12:21 }\end{array}$ \\
\hline Aula 6 & $\begin{array}{l}\text { Vídeo 1: 04:36 } \\
\text { Vídeo 2: 03:54 }\end{array}$ & Aula 14 & Videoconferência \\
\hline Aula 7 & Vídeo 1: 05:40 & Aula 15 & Videoconferência \\
\hline Aula 8 & $\begin{array}{l}\text { Vídeo 1: 03:24 } \\
\text { Vídeo 2: 10:10 } \\
\text { Vídeo 3: 01:43 }\end{array}$ & & \\
\hline
\end{tabular}

Fonte: sistematizado pelos autores

Outra razão para os vídeos serem de curta duração é para não sobrecarregar a memória de trabalho. Do contrário, ocorre um cansaço mental e o aluno desiste de trabalhar o conteúdo.

Outra vantagem de disponibilizar vídeos consistia em oferecer um repositório de explanações que estariam acessíveis sempre que o acadêmico julgasse necessário, o que não ocorria no caso de uma aula presencial. Ou seja, de acordo com a TCC, se a memória de trabalho não tivesse se convertido em memória permanente, o acadêmico teria a oportunidade de rever o vídeo tantas vezes quantas julgasse necessário. Isso não é possível numa aula presencial. 
Os vídeos foram produzidos com o software Icecream Screen Recorder ${ }^{5}$, que possibilita filmar a tela do computador e, ao mesmo tempo, gravar a voz do locutor. É um programa bem simples e intuitivo. Antes de iniciar a gravação, é solicitado que o usuário use o mouse para selecionar a parte da tela que deseja filmar. Através do uso de ícones, também é possível pausar e retomar a gravação. Entretanto, antes da gravação, preparávamos um arquivo com todo o conteúdo julgado essencial, usando até mesmo cores diferentes no texto para facilitar a compreensão e salientar pontos importantes.

Neste caso, trazemos à discussão a terceira diretriz apresentada no Referencial Teórico: "Use diagramas para ajudar os aprendentes a construir uma compreensão mais profunda" (CLARK; NGUYEN; SWELLER, 2006 apud SOUZA, 2010, p. 126). Na preparação do vídeo, o uso de diagramas tornouse essencial para, juntamente com a explicação verbal, minimizar o tempo do vídeo. Entretanto, gastamos por volta de uma hora para produzir um vídeo de até 15 minutos.

Na produção dos vídeos, precisamos, como professor, exercitar a capacidade e a habilidade de ser claro, direto e sucinto, para não divagar além do conteúdo e para permanecer focado naquilo que era importante. Tal fato também nos serviu como um momento de autorreflexão e aprendizado, visto que, se não conseguíssemos expor ou explicar um raciocínio em um curto período de tempo, de forma clara e precisa, não teríamos automatizado o conteúdo (SWELLER, 1976). Portanto, o professor também se encontra num processo contínuo de transformação e aprendizado, o que indica que são necessários mais estudos e reflexões sobre o assunto em questão.

No questionário, apresentamos a seguinte pergunta aos acadêmicos: "Com relação à disciplina de Estruturas Algébricas lecionada em REDE no primeiro semestre de 2020, na sua opinião, quais foram os aspectos positivos?" Vários acadêmicos mencionaram a iniciativa dos vídeos. A seguir, transcrevemos algumas respostas que se referiam a eles.

Acadêmico $A^{6}$ - Didática do professor em gravar vídeos breves [...]

Acadêmico B - A metodologia com vídeos curtos tendo a possibilidade de acessá-los em qualquer momento de estudo [...]

Acadêmico $E-[\ldots]$ com os vídeos bem explicativos antes das tarefas.

Acadêmico $\mathrm{F}-[\ldots]$ outro ponto positivo foram os vídeos gravados para nos auxiliar nas atividades, que foram essenciais e muito bons. Não foram vídeos longos, cansativos e auxiliaram na minha aprendizagem.

A partir dessas manifestações, observamos que a nossa preocupação com a carga cognitiva do acadêmico foi um fator importante e providencial, visto que a maneira de apresentar os vídeos foi muito bem recebida. Dessa forma, defendemos que, dentro dos objetivos da disciplina, a nossa preocupação extrapolou o conteúdo ministrado. Nosso cuidado

\footnotetext{
${ }^{5}$ Disponível em: https://icecreamapps.com/Screen-Recorder/

${ }^{6}$ Com o intuito de preservar o anonimato dos participantes, eles são indicados como Acadêmico A, Acadêmico B, e assim sucessivamente.
} 
centra-se, em especial, na forma como organizamos o ensino de nossas disciplinas [...], partindo do pressuposto de que todos os conhecimentos adquiridos durante a licenciatura, relativos às disciplinas de conteúdo matemático ou às pedagógicas, contribuem para a aprendizagem da docência. (FAJARDO; LOPES, 2017, p. 290)

Os Acadêmicos A e B salientaram a brevidade dos vídeos com um fator positivo. Isso nos remonta à oitava diretriz: "Reduza o conteúdo ao essencial" (CLARK; NGUYEN; SWELLER, 2006 apud SOUZA, 2010, p. 133). Ao preparar os vídeos, levamos isso em consideração. Ao preparar o texto para efetuar a gravação. a reflexão de como reduzir o conteúdo ao essencial foi fundamental para manter o tempo até 15 minutos.

O Acadêmico $B$ também pontuou o fato de poder acessar os vídeos em qualquer momento de estudo. Essa preocupação foi mencionada por nós quando expomos sobre a produção dos vídeos.

Além disso, ela vai ao encontro da décima sexta diretriz: "Dê aos aprendentes o controle sobre o ritmo e gerencie a Carga Cognitiva quando o ritmo tiver de ser controlado pelo sistema instrucional" (CLARK; NGUYEN; SWELLER, 2006 apud SOUZA, 2010, p. 137). Nos vídeos apresentados, os acadêmicos tiveram o controle sobre o ritmo de aprendizagem, pois puderam parar ou até mesmo voltar o vídeo. Com vídeos de curta duração, esse procedimento de controle apresentou-se ainda mais acessível.

Concomitantemente às postagens do conteúdo e dos vídeos na Plataforma Moodle, foram disponibilizadas tarefas correspondendo a uma atividade semanal, bem como dois Fóruns: um de Notícias e um para Discussão. $O$ segundo deles apresentou um desafio. Na sua descrição constava o objetivo de compartilhar as dúvidas e as respostas com todos os participantes, além do fato do acadêmico poder acessá-lo em qualquer momento.

No entanto, o Fórum de Discussão não teve êxito, pois os acadêmicos não postavam as suas dúvidas. Embora saibamos que dúvidas sempre surgem, os alunos não estavam se manifestando. Dessa maneira, criamos um grupo no WhatsApp como uma alternativa pedagógica ao Fórum de Discussão. Essa iniciativa teve sucesso. Todos nós, o professor e os acadêmicos, passamos a interagir de forma colaborativa.

Além disso, no Fórum de Notícias, sempre salientamos a importância do trabalho em grupo, mesmo que virtualmente, e sempre nos manifestamos dispostos a auxiliar por meio de e-mail, Fórum de Discussão e/ou mensagem via Plataforma Moodle, ou através do grupo do WhatsApp, quer pelo grupo criado, quer por mensagem particular. $O$ fator importante era que eles se manifestassem com as suas dúvidas e que elas fossem sanadas; pois, se a dúvida persiste, como pode ocorrer a aprendizagem?

A dúvida do aluno pode ser considerada como uma carga estranha do conteúdo estudado, pois manifesta uma possível barreira na comunicação entre o professor e o aluno (ARTINO, 2008). Cabe, então, ao professor trabalhar para minimizar essa carga, procurando ter uma maior interação com o estudante; e foi isso que procuramos fazer. 
Com relação a esse desafio de falta de participação dos acadêmicos no fórum de discussão, questionamos os acadêmicos com a seguinte indagação: "Se você pudesse escolher entre participar de um Fórum de Discussão no Moodle ou de um grupo no WhatsApp tratando do mesmo assunto, qual seria a sua escolha?". Dos sete participantes que responderam à pergunta, cinco apontaram o aplicativo WhatsApp, e dois optaram pelo Moodle.

Ainda, nesta mesma linha de averiguação, perguntamos: "Na disciplina de Estruturas Algébricas no Moodle foi criado um Fórum de Discussão com o intuito de sanar dúvidas. No entanto, você não participou desse fórum, por quê?". No geral, os acadêmicos responderam que, para eles, era mais fácil usar o aplicativo WhatsApp. Realmente, este aplicativo é de acesso mais rápido e imediato, pois se encontra disponível no nosso telefone celular.

Retornando às tarefas disponibilizadas na Plataforma Moodle, a primeira aula, que foi presencial, consistiu do trabalho cooperativo durante a "não pandemia", conforme já exposto na metodologia. No momento presencial, a tarefa era dada como concluída somente quando todos haviam sanado as suas dúvidas.

Com a atividade em REDE, a apresentação na lousa não estava ocorrendo. Então, como poderíamos avaliar o nível de compreensão dos acadêmicos? O procedimento adotado foi o de corrigir individualmente as tarefas, incluindo comentários nessa correção e solicitando ao acadêmico que reenviasse as que necessitavam de melhorias. ${ }^{7}$ Nós as devolvíamos aos acadêmicos via email antes da divulgação da nova tarefa, tendo em vista que o conhecimento prévio era essencial para o entendimento do seguinte. Ou seja, se isso não fosse feito, estaríamos criando uma carga estranha em relação ao próximo conteúdo, pois não estaríamos nos comunicando de maneira eficaz à transmissão do conteúdo (ARTINO, 2008).

Os acadêmicos se manifestaram de maneira positiva em relação à metodologia de corrigir as tarefas e retorná-las por e-mail em tempo hábil. $O$ Acadêmico D escreveu que "[...] o retorno das tarefas que o professor fez foi muito importante para perceber os erros e corrigi-los". Por sua vez, o acadêmico A comentou: "gostei muito da maneira que a aula foi conduzida, e a disponibilidade com o tempo de postagem e do atendimento do professor".

Ao longo do semestre, à medida que as semanas iam transcorrendo, sentíamos a carência de algo. Concluímos que essa carência estava relacionada à falta de momentos síncronos virtuais, em que podemos interagir em tempo real. Assim, conforme consta no quadro 1, nas três últimas aulas tivemos reuniões via videoconferência com o uso da ferramenta Google Meet. Nesses momentos, sanamos dúvidas em tempo real. Alguns acadêmicos fizeram algumas apresentações de conteúdo relacionadas à disciplina e também conversamos sobre outros assuntos, em um momento de descanso mental. Os acadêmicos consideraram um ponto negativo na disciplina o fato de ter havido somente três videoconferências. Sobre esse tópico, o Acadêmico E manifestou-se, mencionando:

acredito que poderiam ter mais discussões pelo google meet, não necessariamente toda semana, mas a cada 2 ou 3 semanas, pois

\footnotetext{
${ }^{7}$ Vale ressaltar que as tarefas eram entregues via Moodle, através de uma atividade de upload, sendo o arquivo solicitado no formato "*.pdf".

Revista de Estudos e Pesquisas sobre Ensino Tecnológico, v. 6, Edição Especial Desafios e Avanços 11 Educacionais em Tempos da COVID-19, e155720, 2020.
} 
assim o entendimento das dúvidas é maior e gera uma discussão sobre as diferentes formas de demonstrar uma mesma afirmação, agregando maiores conhecimentos. Além disso, nesse momento de distanciamento considero importantes momentos de socialização. (Acadêmico E)

Toda nova experiência é uma oportunidade para aprender e se aperfeiçoar. Portanto, tomamos o comentário do Acadêmico E como muito importante. Cremos que, numa próxima oportunidade, seria de bom tom haver uma reunião virtual semanal para dialogar, sanar dúvidas e, assim, socializar. $\mathrm{Na}$ manifestação do Acadêmico $\mathrm{E}$ parece estar presente $\mathrm{o}$ fato da não socialização ser uma carga estranha à aprendizagem, visto que conforme Artino (2008) essa carga está diretamente relacionada à comunicação entre o aluno e o professor.

$\mathrm{O}$ acadêmico $\mathrm{F}$ também apresentou uma preocupação similar:

Como a proposta de trabalhar pelo REDE foi algo colocado imediatamente pela universidade, senti falta nas primeiras semanas de encontros virtuais para discutirmos e compartilharmos ideias das atividades propostas, mas nada grave que tenha atrapalhado no andamento da disciplina, pois os outros materiais utilizados pelo professor deram conta. (Acadêmico F)

As manifestações dos Acadêmicos $E$ e $F$, apresentadas aqui, foram respostas à pergunta: "Com relação à disciplina de Estruturas Algébricas lecionada em REDE no primeiro semestre de 2020, na sua opinião, quais foram os aspectos negativos (O que poderia melhorar)?". Sobre este aspecto, o acadêmico G, estando de acordo com o acadêmico $E$, também se manifestou: "acredito que uma frequência maior de encontros virtuais para discussão acerca das aulas e atividades propiciaria debates ricos, assim como esclarecimento de dúvidas".

Nesses comentários, podemos vislumbrar que se encontra subjacente o aspecto social do ser humano, que é uma necessidade de comunicar pessoalmente. Ou seja, parece que a falta de uma comunicação física gera uma carga estranha ao processo de ensino e aprendizagem (ARTINO, 2008).

$\mathrm{Na}$ sequência, transcrevemos as respostas dos outros acadêmicos.

Acadêmico A - No início eram muitos exercícios, claro que tínhamos ajuda do professor e colegas, mas talvez cuidar isso...

Acadêmico B - Não identifico, pois dentro da incerteza do momento teve o objetivo alcançado de oportunizar aprendizado.

Acadêmico $C$ - De não ter sido presencialmente as aulas. Acredito que não teve ponto negativo, porque o professor buscou sempre estar à disposição para tirarmos as dúvidas.

Acadêmico $D-O$ aspecto negativo que mais interferiu foi a falta de interação com os colegas e com o professor. Neste item os colegas já sugeriram que sejam feitas mais aulas em vídeo. Visto que, esse semestre foi de aprendizado não só da disciplina, mas também de ter uma disciplina em rede.

O acadêmico A manifestou-se negativamente com relação ao fato de haver muitos exercícios no início. Esse comentário é muito relevante, visto que, quando a disciplina foi ministrada antes da pandemia, observávamos o avanço de cada acadêmico, ao circular pela aula. E, no caso de algum deles não ter

Revista de Estudos e Pesquisas sobre Ensino Tecnológico, v. 6, Edição Especial Desafios e Avanços 12 Educacionais em Tempos da COVID-19, e155720, 2020. 
concluído a tarefa e o tempo da aula ter terminado, optávamos por continuar a tarefa na próxima aula. Ou seja, havia flexibilidade com relação ao tempo de conclusão, levando em consideração o desenvolvimento e a aprendizagem do acadêmico.

No caso da disciplina durante a pandemia, não efetuamos esse monitoramento. Daí decorre a manifestação do Acadêmico A, que assim, parece ter criado uma carga estranha à aprendizagem, pois houve uma falta de comunicação entre aluno e professor (ARTINO, 2008). No entanto, salientamos, ainda, que estipulamos o período de uma semana para entregar a tarefa. Mas tal período não era rígido, pois, na Plataforma Moodle, a atividade de upload não estava condicionada a uma data limite, e o aluno podia entregar qualquer tarefa até o final do semestre. Isso foi feito tendo em vista garantir a aprendizagem do acadêmico, assim como manter o estímulo de continuar os estudos, visto que bloquear o recebimento da tarefa na Plataforma Moodle poderia resultar numa desistência.

Ocorreu que alguns acadêmicos não entregaram as tarefas regularmente, acumulando-as até o final do semestre. Entretanto, justificaram o atraso, por iniciativa própria, mencionando que tiveram desafios devido à excepcionalidade do isolamento social. Ainda, questionaram se poderiam entregar as tarefas em atraso. Manifestamo-nos positivamente, incentivandoos a executar as tarefas e entregá-las. Dos dez alunos matriculados na disciplina, todos finalizaram as tarefas e efetuaram a sua autoavaliação.

Conforme mencionamos em relação ao desenvolvimento da disciplina antes da pandemia, no final do semestre, os acadêmicos também preencheram um formulário de autoavaliação, pois acreditamos que tal procedimento colabora para uma avaliação formativa e reflexiva. No entanto, incluímos mais uma pergunta, a saber: "Você realizou as tarefas propostas?", com o intuito de gerar a reflexão sobre o seu desenvolvimento ao longo do semestre. Além do mais, por ser uma disciplina de pós-graduação, os acadêmicos têm mais maturidade e levam a sério a sua atribuição de nota com uma justificativa.

Com relação à didática do professor na disciplina, o Acadêmico $\mathrm{C}$ escreveu que

\begin{abstract}
todas as aulas apresentadas pela Rede nessa disciplina foram positivas. Por quê? Porque primeiramente o professor pensou em uma didática no qual alcançaria aqueles alunos que porventura não pudessem acessar as aulas. Outro ponto importante de destacar é a forma como foram explicados os conteúdos, eu, por exemplo, foi a primeira vez que tive acesso à Estruturas Algébricas e essa disciplina como ponto positivo me fez pensar como posso ensinar os meus alunos, por exemplo, com as demonstrações tanto na prática quanto na teoria. (Acadêmico $\mathrm{C}$ )
\end{abstract}

Concluímos, pela manifestação do Acadêmico C, que levar em consideração a Teoria da Carga Cognitiva (SWELLER, 1976) foi um fator importante no desenvolvimento das aulas. Ainda sobre este aspecto, o Acadêmico $E$ externou que "a dinâmica das atividades foram boas, com os grupos [virtuais] da disciplina pra tirar dúvidas com os colegas e com os vídeos bem explicativos antes das tarefas". 
Seguindo na linha da didática aplicada na disciplina, o Acadêmico $F$ manifestou-se da seguinte maneira:

\begin{abstract}
Um dos pontos positivos com relação à disciplina foi a dedicação e a disponibilidade do professor a se desafiar e assim continuar a ministrar a disciplina pelo REDE. Por mais que não estávamos interagindo presencialmente com os colegas e o professor [...]. Os encontros [virtuais] para tirar dúvidas com relação às atividades também foi outro aspecto positivo, que me permitiu ouvir as dúvidas dos colegas, expor as minhas, compartilhar os conhecimentos e assim amadurecer as ideias para a realização das mesmas. Os comentários realizados nas atividades também me ajudaram a refletir e visualizar meus erros. (Acadêmico $F$ )
\end{abstract}

Tínhamos uma preocupação constante com os discentes, desejando sempre oportunizar a aprendizagem. Isso é corroborado pela manifestação do Acadêmico G: "O professor conduziu as aulas de uma forma atenciosa e compreensível de acordo com o contexto atual, utilizando-se de materiais adaptáveis, além de priorizar a compreensão dos estudantes".

Ao finalizarmos a análise do questionário, apresentamos a quarta diretriz: "Explique diagramas com palavras apresentadas em 'áudio-narração" (CLARK; NGUYEN; SWELLER, 2006 apud SOUZA, 2010, p. 127). Pois, conforme Souza, temos que

a Teoria da Carga Cognitiva supõe que a Memória de Trabalho possui múltiplos sistemas de armazenagem, sendo um para informações visuais e outro para informações auditivas. A utilização do texto falado em uma apresentação canaliza essas "informações auditivas" para o "subcomponente auditivo da Memória de Trabalho" ("ciclo fonológico"), liberando o "canal visual" (subcomponente visual da Memória de Trabalho) para o processamento de outras informações, impedindo assim que ele seja sobrecarregado. (SOUZA, 2010, p. 128)

A quarta diretriz complementa a terceira, pois não há sentido em apresentarmos um texto denso na produção de um vídeo onde haverá uma narração verbal. O uso de diagramas minimizará a carga estranha, visto que o aluno poderá usufruir da memória de trabalho de uma maneira mais completa, a saber: o armazenamento visual e auditivo.

\title{
Conclusão
}

Ao longo deste artigo discutimos a problemática se os procedimentos metodológicos usados na disciplina, ministrada no formato REDE, resultaram num momento de aprendizagem satisfatório para os acadêmicos. Para tanto, fizemos uma comparação da disciplina ministrada em momento de não pandemia e pandemia; apresentamos desafios, reflexões e ações docentes no trabalho, e identificamos as impressões dos acadêmicos por meio de um questionário.

Usamos como balizador a Teoria da Carga Cognitiva, apresentada por Sweller (1976), que estipula a formação de esquemas mentais e define como automatizá-los, tornando-os parte da memória permanente. Conforme as respostas às perguntas do questionário, concluímos que fomos felizes no caminho metodológico adotado. 
Certamente, aderir ao REDE foi um desafio, em que aprendemos novos caminhos metodológicos, especialmente o AVEA. Nesse sentido, postulamos que "não há ensino sem pesquisa e pesquisa sem ensino" (FREIRE, 2011, p. 30). Logo, estamos em sintonia com essa asserção, visto que foi necessário pesquisar para lecionar a disciplina. Por outro lado, esse ensino possibilitou esta pesquisa. "Enquanto ensino, continuo buscando, reprocurando. Ensino porque busco, porque indaguei, porque indago e me indago" (Ibid, p. 30).

O isolamento social, decorrente da COVID-19, tirou todos da sua zona de conforto. Assim, continuamos nos aperfeiçoando, na medida em que indagamos e somos indagados. Isso gera uma autorreflexão, essencial para favorecer a mudança de ensinar na sala de aula. É claro que, para isso ocorrer, precisamos concordar que a sala de aula não pode ser um local estanque.

Com a produção de vídeos de curta duração, nós tivemos que exercitar a nossa capacidade de claro, direto e sucinto, o que normalmente não ocorre numa aula presencial. Nesse sentido, estarmos cientes das cargas intrínseca, estranha e relevante nos auxiliou em compreender a importância de refletir ao preparar as aulas no formato REDE.

De qualquer forma, alguém poderia contra-argumentar que uma aula de duas horas ou mais poderia ocorrer por videoconferência, ser gravada e, após, disponibilizada a todos os acadêmicos. No entanto, nós voltamos a salientar a carga estranha que é gerada com essa situação, questionando: quem assistiria a esse vídeo várias vezes? Tal pergunta nos remete à décima sexta diretriz (SOUZA, 2010), que visa auxiliar o acadêmico a gerenciar o seu tempo.

O tempo é uma carga estranha, quando não gerenciado eficazmente. A um vídeo explicativo de curta duração, verificamos que os acadêmicos se sentiriam muito mais estimulados a revê-lo. Além do mais, ainda não há uma ferramenta universal de busca ${ }^{8}$ num vídeo qualquer, como existe no arquivo em formato PDF, que permite procurar por palavras dentro do texto.

Tais questionamentos nos fazem refletir sobre a aula presencial que apresentávamos antes da pandemia. No período pós-pandemia, ela será a mesma?

\section{Referências}

ARTINO, A. R. Jr. Cognitive load theory and the role of learner experience: An abbreviated review for educational practitioners. AACE Journal, v. 16, n. 4, p. 425-439, 2008.

ATKINSON, T. C.; SHIFFRIN, R. M. Human memory: a proposed system and its control processes. In: SPENCE, K. W.; SPENCE, J. T. (Ed.).The psychology of learning and motivation: advances in research and theory. New York: Academic Press, 1968.

BROOKS, S. K. et al. The psychological impact of quarantine and how to reduce it: rapid review of the evidence. The Lancet, v. 395, n. 10227, p. 912-

${ }^{8}$ Até o momento, sabemos que isso é possível em vídeos do Youtube.

Revista de Estudos e Pesquisas sobre Ensino Tecnológico, v. 6, Edição Especial Desafios e Avanços 15 Educacionais em Tempos da COVID-19, e155720, 2020. 
920, n. 14, Feb. 2020. Disponível em: https://doi.org/10.1016/S01406736(20)30460-8. Acesso em: 21 set. 2020.

CHIZZOTTI, A. Pesquisa em Ciências Humanas e Sociais. São Paulo: Cortez, 2017.

CLARK, R.; NGUYEN, F.; SWELLER, J. Efficiency in Learning: evidencebased guidelines to manage cognitive load. San Francisco: John Wiley \& Sons, 2006.

FAJARDO, R.; LOPES, A. R. L. V. Alguns apontamentos sobre a avaliação no curso de licenciatura em Matemática a partir de uma experiência. Educação Matemática em Revista, Brasília, v. 22, n. 56, p. 289-303, out./dez. 2017. Disponível em: http://sbem.iuri0094.hospedagemdesites.ws/revista/index.php/emr/article/vie w/851. Acesso em: 15 set. 2020.

FERNANDES, C. O.; FREITAS, L. C. Indagações sobre o currículo: currículo e avaliação. Brasília: Ministério da Educação, Secretaria de Educação Básica, 2007.

FREIRE, P. Pedagogia da autonomia: saberes necessários à prática educativa. São Paulo: Paz e Terra, 2011.

SOUZA, N. P. C. de. Teoria da carga cognitiva: origem, desenvolvimento e diretrizes aplicáveis ao processo ensino-aprendizagem. 2010. Dissertação (Mestrado Educação em Ciências e Matemáticas). Universidade Federal do Pará. Belém, 2010. Disponível em: https://www.researchgate.net/publication/262676606_Teoria_da_Carga_Cog nitiva_Origem_Desenvolvimento_e_Aplicacoes. Acesso em: 20 fev. 2020.

SWELLER, J. The effect of task complexity and sequence on rule learning and problem solving. British Journal of Psychology, v. 67. N. 4, p. 553-558, 1976. Disponível em: https://doi.org/10.1111/j.2044-8295.1976.tb01546.x. Acesso em: 01 mar. 2020.

SWELLER, J.; CHANDLER, P. Why some material is difficult to learn. Cognition and Instruction, v.12, n. 3, p. 185-233, 1994.

UNIVERSIDADE FEDERAL DE SANTA MARIA. Pró-Reitoria de Graduação. Instrução Normativa N. 02/2020/PROGRAD. Santa Maria, 2020. Disponível em: https://www.ufsm.br/app/uploads/2020/03/IN-002-2020-PROGRADUFSM.pdf. Acesso em: 20 mar. 2020.

VIGOTSKY, L. S. A construção do pensamento e da linguagem. São Paulo: Martins Fontes, 2000.

VIGOTSKY, L. S. A formação social da mente: o desenvolvimento dos processos psicológicos superiores. 6. ed. São Paulo: Martins Fontes, 2002. 
Recebido: $13 / 11 / 2020$

Aprovado: 07/12/2020

Como citar: FAJARDO, R.; ZIMMERMANN, S. S. Uma análise de procedimentos metodológicos executados numa disciplina de Matemática na Pós-Graduação durante a pandemia da COVID-19.

Revista de Estudos e Pesquisas sobre Ensino Tecnológico (EDUCITEC), v. 6, Ed. Esp.

Desafios e avanços educacionais em tempos da COVID-19, e155720, 2020.

Direito autoral: Este artigo está licenciado sob os termos da Licença Creative CommonsAtribuição 4.0 Internacional.

\section{(c) (i)}

